\title{
The TRINITY Study: distribution of systolic blood pressure reductions
}

\author{
This article was published in the following Dove Press journal: \\ Integrated Blood Pressure Control \\ II July 2013 \\ Number of times this article has been viewed
}

\author{
Danny H Sugimoto' \\ Steven G Chrysant ${ }^{2}$ \\ Michael Melino ${ }^{3}$ \\ James Lee $^{3}$ \\ Victor Fernandez ${ }^{3}$ \\ Reinilde Heyrman ${ }^{4}$ \\ 'Cedar-Crosse Research Center and \\ Rush Medical College, Chicago, IL, \\ USA; ${ }^{2}$ Oklahoma Cardiovascular and \\ Hypertension Center and Department \\ of Cardiology, University of Oklahoma \\ College of Medicine, Oklahoma City, \\ OK, USA; ${ }^{3}$ Department of Clinical \\ Development, Daiichi Sankyo, Inc, \\ Parsippany, NJ, USA; ${ }^{4}$ Formerly of the \\ Department of Clinical Development, \\ Daiichi Sankyo, Inc, Parsippany, \\ NJ, USA
}

Correspondence: Danny H Sugimoto Cedar-Crosse Research Center, 800 S Wells St, Suite MI5,

Chicago, IL, USA 60607

$\mathrm{Tel}+\mathrm{I} 31243 \mid 6765$

Fax + I 3124317959

Email dsugimoto@cedarcrosse.com
Background: Elevated systolic blood pressure is more difficult to control than elevated diastolic blood pressure. The objective of this prespecified analysis of the Triple Therapy with Olmesartan Medoxomil, Amlodipine, and Hydrochlorothiazide in Hypertensive Patients Study (TRINITY) was to compare the efficacy of olmesartan medoxomil (OM) $40 \mathrm{mg}$, amlodipine besylate (AML) $10 \mathrm{mg}$, and hydrochlorothiazide (HCTZ) $25 \mathrm{mg}$ triple-combination treatment with the component dual-combination treatments in reducing elevated seated systolic blood pressure (SeSBP).

Methods: The 12-week TRINITY study randomized participants to either one of the three component dual-combination treatments (OM 40 mg/AML 10 mg, OM 40 mg/HCTZ 25 mg, or AML $10 \mathrm{mg} / \mathrm{HCTZ} 25 \mathrm{mg}$ ) or the triple-combination treatment. The primary outcome of this analysis was the categorical distribution of SeSBP reductions at week 12 from baseline with OM $40 \mathrm{mg} / \mathrm{AML} 10 \mathrm{mg} / \mathrm{HCTZ} 25 \mathrm{mg}$ versus the dual-combination treatments.

Results: SeSBP reductions $>50 \mathrm{mmHg}$ were seen in $24.4 \%$ of participants receiving triplecombination treatment versus $8.1 \%-15.8 \%$ receiving dual-combination treatment. More participants receiving triple-combination treatment achieved the SeSBP target of $<140 \mathrm{mmHg}$ (73.6\% versus $51.3 \%-58.8 \% ; P<0.001)$ and the seated blood pressure target of $<140 / 90 \mathrm{mmHg}$ (69.9\% versus $41.1 \%-53.4 \% ; P<0.001)$. Prevalence and severity of adverse events were similar in all treatment groups.

Conclusion: Treatment with OM $40 \mathrm{mg} / \mathrm{AML} 10 \mathrm{mg} / \mathrm{HCTZ} 25 \mathrm{mg}$ was well tolerated and more effective in reducing SeSBP than the dual-combination treatments.

Keywords: olmesartan, angiotensin receptors, calcium channel blockers, thiazide diuretics, hypertension, TRINITY

\section{Introduction}

Approximately 33\% of adults in the US (representing 78 million adults) have hypertension, one of the most prevalent risk factors for development of cardiovascular disease. ${ }^{1}$ The risks of ischemic heart disease, heart failure, stroke, and kidney disease have all been shown to correlate directly with elevated blood pressure (BP). ${ }^{2}$

Historically, assessments of cardiovascular risk have focused on elevated diastolic BP (DBP) ${ }^{3}$ however, DBP tends to level off or decrease after age 50 years, whereas systolic BP (SBP) continues to rise throughout life. ${ }^{2}$ In a recent analysis of data from the National Health and Nutrition Examination Survey, mean SBP increased with advancing age from $115 \mathrm{mmHg}$ (ages 18-39 years) to $123 \mathrm{mmHg}$ (ages 40-59 years) to $136 \mathrm{mmHg}$ (age $\geq 60$ years). ${ }^{4}$ In contrast, mean DBP rose from $69 \mathrm{mmHg}$ to $75 \mathrm{mmHg}$ as age increased from 18-39 years to 40-59 years, but then decreased to $68 \mathrm{mmHg}$ as age further increased to $\geq 60$ years. $^{4}$ Thus, systolic hypertension increases in prevalence 
with age, becoming the most common form of hypertension after age 50 years. ${ }^{2,5}$

Systolic hypertension is a major risk factor for the development of cardiovascular disease, and data show that it is a more potent and accurate predictor of cardiovascular morbidity and mortality than diastolic hypertension in individuals $\geq 50$ years of age..$^{2,3,6,7}$ In a meta-analysis of data from 61 trials, SBP was found to have approximately $20 \%$ greater predictive power for ischemic heart disease mortality than DBP. ${ }^{6}$ Furthermore, clinical trials demonstrate that reducing SBP improves cardiovascular outcomes. ${ }^{2}$ Another meta-analysis of data from ten trials found that improvements in cardiovascular event rates were related to reductions in SBP but not to reductions in DBP. ${ }^{8}$

Despite these data, systolic hypertension is frequently less well controlled than diastolic hypertension. ${ }^{2,9}$ After 3 years of therapy in the Antihypertensive and Lipid-Lowering Treatment to Prevent Heart Attack Trial (ALLHAT), only $64 \%$ of patients had their SBP adequately controlled compared with $90 \%$ who had their DBP adequately controlled. ${ }^{9}$ This inadequate management of systolic hypertension is a major contributing factor to the low rate of overall BP control. ${ }^{2}$ It is estimated that $80 \%$ of individuals with hypertension in the US will be $>50$ years of age and have predominantly SBP elevations by $2020 .{ }^{10}$ With the aging of the US population, reducing cardiovascular morbidity and mortality will require greater emphasis on successfully managing systolic hypertension. ${ }^{2}$

The primary study results for the Triple Therapy with Olmesartan Medoxomil, Amlodipine, and Hydrochlorothiazide in Hypertensive Patients Study (TRINITY; ClinicalTrials.gov identifier: NCT00649389) have been published previously. ${ }^{11}$ The triple-drug combination of olmesartan medoxomil (OM) $40 \mathrm{mg}$, amlodipine besylate (AML) $10 \mathrm{mg}$, and hydrochlorothiazide (HCTZ) $25 \mathrm{mg}$ reduced both seated DBP (primary efficacy registration requirement for OM/ AML/HCTZ) and seated SBP (SeSBP) to a greater extent and enabled a larger proportion of study participants to reach BP goal than all three component dual-combination treatments. ${ }^{11}$ We report here the unique results of a prespecified TRINITY analysis that evaluated categorical mean reductions in SeSBP with OM 40/AML 10/HCTZ 25 mg compared with each of the component dual-combination treatments.

\section{Methods}

\section{Study population}

The detailed study design and principal efficacy and safety results have been reported previously in the primary
TRINITY publication. ${ }^{11}$ Briefly, TRINITY was a 12-week, prospective, randomized, double-blind, parallel-group evaluation conducted on an outpatient basis at 317 clinical sites in the US and Puerto Rico. Individuals $\geq 18$ years of age with a mean SeBP $\geq 140 / 100 \mathrm{mmHg}$ or $\geq 160 / 90 \mathrm{mmHg}$ (off antihypertensive medication) were eligible for randomization provided they did not have a recent ( $\leq 6$ months) history of myocardial infarction, coronary revascularization, or unstable angina; New York Heart Association class 3 or 4 congestive heart failure; severe renal insufficiency (defined as creatinine clearance $<30 \mathrm{~mL} /$ minute); or uncontrolled diabetes (defined as hemoglobin A1c levels $>9 \%$ ). Individuals with type 1 or type 2 diabetes mellitus that was controlled by diet, insulin, or oral hypoglycemic agents on a stable dose for $\geq 30$ days were eligible for participation. The study was conducted in accordance with the Declaration of Helsinki; the study protocol and consent forms were approved by the appropriate institutional review boards; and all individuals provided written informed consent before participation in any study procedures.

\section{Study design}

The study included a 3-week washout period for participants already taking antihypertensive medications, followed by a 12-week double-blind treatment period (Figure 1). ${ }^{11}$ Eligible participants were randomized (stratified by age, race, and diabetes status) at the start of the study to a treatment sequence that led to their final treatment assignment: either one of the three component dual-combination treatments or the triple-combination treatment (OM $40 \mathrm{mg} / \mathrm{AML}$ $10 \mathrm{mg} / \mathrm{HCTZ} 25 \mathrm{mg}$ [given as the OM $40 \mathrm{mg} / \mathrm{HCTZ} 25 \mathrm{mg}$ fixed-dose combination plus AML $10 \mathrm{mg}$ given separately], OM $40 \mathrm{mg} / \mathrm{AML} 10 \mathrm{mg}$ [fixed-dose combination], OM $40 \mathrm{mg} / \mathrm{HCTZ} 25 \mathrm{mg}$ [fixed-dose combination], or AML $10 \mathrm{mg} / \mathrm{HCTZ} 25 \mathrm{mg}$ [given separately]). All participants received dual-combination treatment for 2 weeks, except for a subset of 36 study participants who had not been taking antihypertensive medications for at least 3 weeks who received placebo for 2 weeks (to assess the study for nontreatmentassociated BP effects, some patients received placebo for 2 weeks). All participants assigned to dual-combination treatment remained on their assigned treatment until week 4. All participants taking placebo at week 2 were switched to one of the three dual-combination treatments from week 2 to week 4. At week 4, participants were either maintained on dual-combination treatment to week 12 or switched to triplecombination treatment with OM $40 \mathrm{mg} / \mathrm{AML} 10 \mathrm{mg} / \mathrm{HCTZ}$ $25 \mathrm{mg}$ until week 12. Participants were instructed to take 


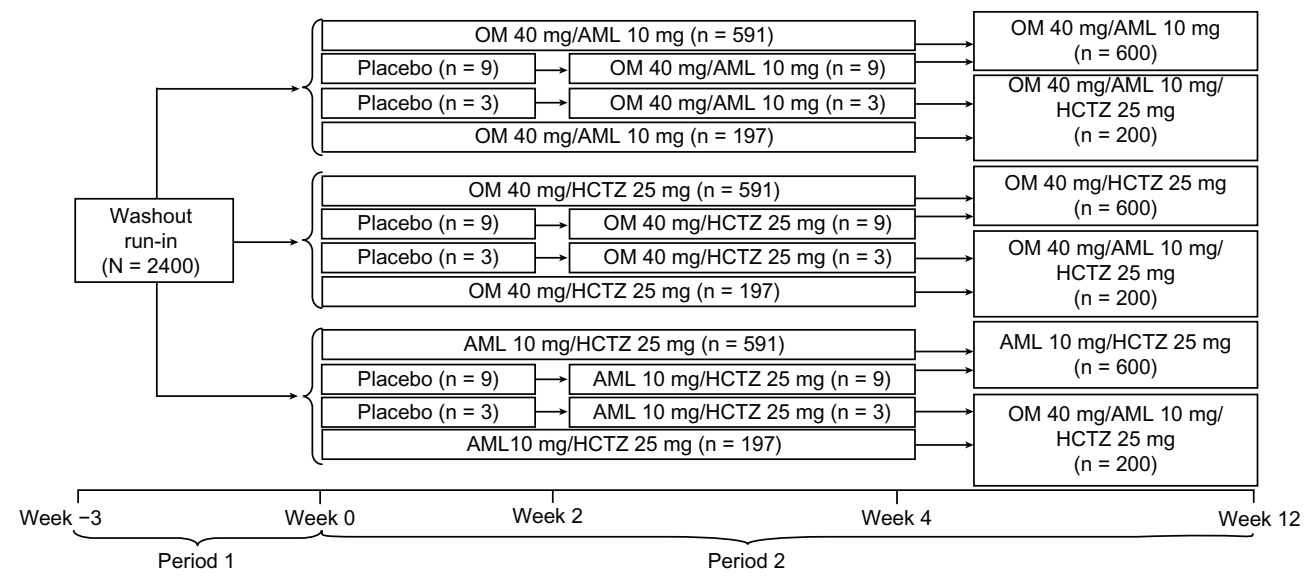

Figure I Study design.

Note: Modified with permission from Oparil et al." Copyright Elsevier (2010).

Abbreviations: $\mathrm{N}$, total sample size; $\mathrm{n}$, number; OM, olmesartan medoxomil; AML, amlodipine besylate; HCTZ, hydrochlorothiazide.

all medications at the same time ( \pm 2 hours) each day, and participants and investigators remained blinded as to which drugs were being administered at any given time during the double-blind treatment period.

\section{Efficacy assessments}

The primary assessment for the present analysis was the distribution (or range) of SeSBP reductions at week 12 from baseline with triple-combination treatment compared with the component dual-combination treatments. For this assessment, reductions in SeSBP were categorized as $>50,>40$ to $\leq 50,>30$ to $\leq 40,>20$ to $\leq 30,>10$ to $\leq 20$, and $\leq 10 \mathrm{mmHg}$. Additional assessments (post hoc analyses) included the least squares mean reduction in SeSBP, the proportion of participants achieving the SeSBP target of $<140 \mathrm{mmHg}$, and the proportion of participants achieving the SeBP target of $<140 / 90 \mathrm{mmHg}$ by treatment within each SeSBP reduction category.

\section{Safety assessments}

Safety was assessed at all visits. Safety parameters evaluated included adverse events, physical examinations, twelvelead electrocardiograms, and clinical laboratory tests. For this analysis, safety parameters were categorized based on randomized treatment assignment and degree of SeSBP reduction ( $\leq 40$ or $>40 \mathrm{mmHg}$ ).

\section{Statistical analysis}

Efficacy was assessed in all study participants who had a baseline assessment of SeBP, received at least one dose of study medication, and had at least one postdose assessment of SeBP. To account for potential early termination during the double-blind treatment period, efficacy analyses were conducted by a last observation carried forward approach. Safety was assessed in all participants who received at least one dose of study medication at or beyond the week 4 visit (ie, the first time at which participants could receive triple-combination treatment). Both efficacy and safety were categorized on the basis of the degree of SeSBP reduction at week 12.

Changes in SeBP at week 12 were evaluated with an analysis of covariance model with baseline SeBP as a covariate and final randomized treatment, subgroup, and final randomized treatment by subgroup interaction as fixed effects. Least squares mean differences and standard errors, derived from this model, were used to calculate baseline changes in SeBP; 2 -sided $P$-values were used to test the significance of these changes for study participants receiving triple-combination treatment versus each dual-combination treatment.

The proportion of study participants achieving SeSBP reductions of $>50 \mathrm{mmHg},>40 \mathrm{mmHg}$ to $\leq 50 \mathrm{mmHg}$, $>30 \mathrm{mmHg}$ to $\leq 40 \mathrm{mmHg},>20 \mathrm{mmHg}$ to $\leq 30 \mathrm{mmHg}$, $>10 \mathrm{mmHg}$ to $\leq 20 \mathrm{mmHg}$, and $\leq 10 \mathrm{mmHg}$ and the proportion of study participants reaching SeSBP $(<140 \mathrm{mmHg})$ and SeBP $(<140 / 90 \mathrm{mmHg})$ targets within these reduction categories were summarized by randomized treatment assignment using descriptive statistics. Overall treatment effects were assessed with the $\chi^{2}$ test, and between-treatment effects were assessed with Fisher's exact test.

\section{Results \\ Study population}

Of the 6724 individuals who were screened, 2492 were randomized and entered the double-blind treatment period, 
and 2116 completed the trial. ${ }^{11}$ The safety population included 2302 participants. The demographic and clinical characteristics at baseline by treatment assignment were similar for randomized study participants (data published in the primary TRINITY paper). ${ }^{11}$ Overall, $52.9 \%$ of participants were male, $66.8 \%$ were white, $30.4 \%$ were black, $9.1 \%$ had chronic cardiovascular disease, $15.5 \%$ had diabetes, and $4.1 \%$ had chronic kidney disease. Mean age (standard deviation [SD]) was 55.1 (10.9) years (18.9\% $\geq 65$ years $)$, and mean body mass index (SD) was $33.1(7.1) \mathrm{kg} / \mathrm{m}^{2}\left(62.4 \% \geq 30 \mathrm{~kg} / \mathrm{m}^{2}\right)$. The mean (SD) duration of hypertension was 9.9 (9.6) years, and mean baseline SeBP was $168.5 / 100.9 \mathrm{mmHg}{ }^{11}$

\section{Efficacy}

Triple-combination treatment resulted in greater SeSBP reductions than the dual-combination treatments (Figure 2). SeSBP reductions of $>50 \mathrm{mmHg}$ were seen in $24.4 \%$ of participants receiving OM $40 \mathrm{mg} / \mathrm{AML} 10 \mathrm{mg} / \mathrm{HCTZ} 25 \mathrm{mg}$, but in only $8.1 \%, 9.5 \%$, and $15.8 \%$ of participants receiving AML $10 \mathrm{mg} / \mathrm{HCTZ} 25 \mathrm{mg}$, OM $40 \mathrm{mg} / \mathrm{AML} 10 \mathrm{mg}$, and OM $40 \mathrm{mg} / \mathrm{HCTZ} 25 \mathrm{mg}$, respectively. SeSBP reductions of $>40 \mathrm{mmHg}$ to $\leq 50 \mathrm{mmHg}$ were seen in $23.0 \%$ of participants receiving triple-combination treatment compared with $14.2 \%-17.6 \%$ of participants receiving dual-combination treatments. SeSBP reductions of $\leq 20 \mathrm{mmHg}$ were seen in only $12.9 \%$ of participants receiving triple-combination treatment compared with $21.8 \%-28.3 \%$ of participants receiving dual-combination treatments. As a result, the overall least squares mean reduction in SeSBP was significantly greater (-37.1 $\mathrm{mmHg}$ versus $-27.5 \mathrm{mmHg}$ to $-30.0 \mathrm{mmHg}$, respectively; $P<0.0001)$, ${ }^{11}$ and the overall mean SeBP was significantly lower $(129.8 / 79.4 \mathrm{mmHg}$ versus $137.0 / 83.2 \mathrm{mmHg}$ and 140.0/86.4 $\mathrm{mmHg}$, respectively; $P<0.0001)$ at week 12 in participants receiving triple-combination treatment than in those receiving dual-combination treatment.

For a given categorical SeSBP reduction, the baseline and week 12 SeSBP levels were similar across treatment groups (Figure 3). In general, the degree of SeSBP reduction correlated with baseline pressure (ie, the higher the SeSBP at baseline, the greater the reduction at week 12). The study participants who had the highest mean SeSBP levels at baseline (176-188 $\mathrm{mmHg}$, depending on treatment) experienced the greatest therapeutic effect (lowest mean SeSBP levels) at week 12 (116-129 mmHg, depending on treatment).

Overall, triple-combination treatment was significantly more effective than the dual-combination treatments in achieving the SeSBP target of $<140 \mathrm{mmHg}(73.6 \%$ versus $51.3 \%-58.8 \%$, respectively) and the SeBP target of $<140 / 90 \mathrm{mmHg}(69.9 \%$ versus $41.1 \%-53.4 \%$, respectively) at week $12(P<0.001$ for all triple- versus dual-combination comparisons). ${ }^{11}$ The higher the categorical SeSBP reduction, the more the observed differentiation based on treatment potency, and as a result, more participants with higher baseline BP had greater achievement of

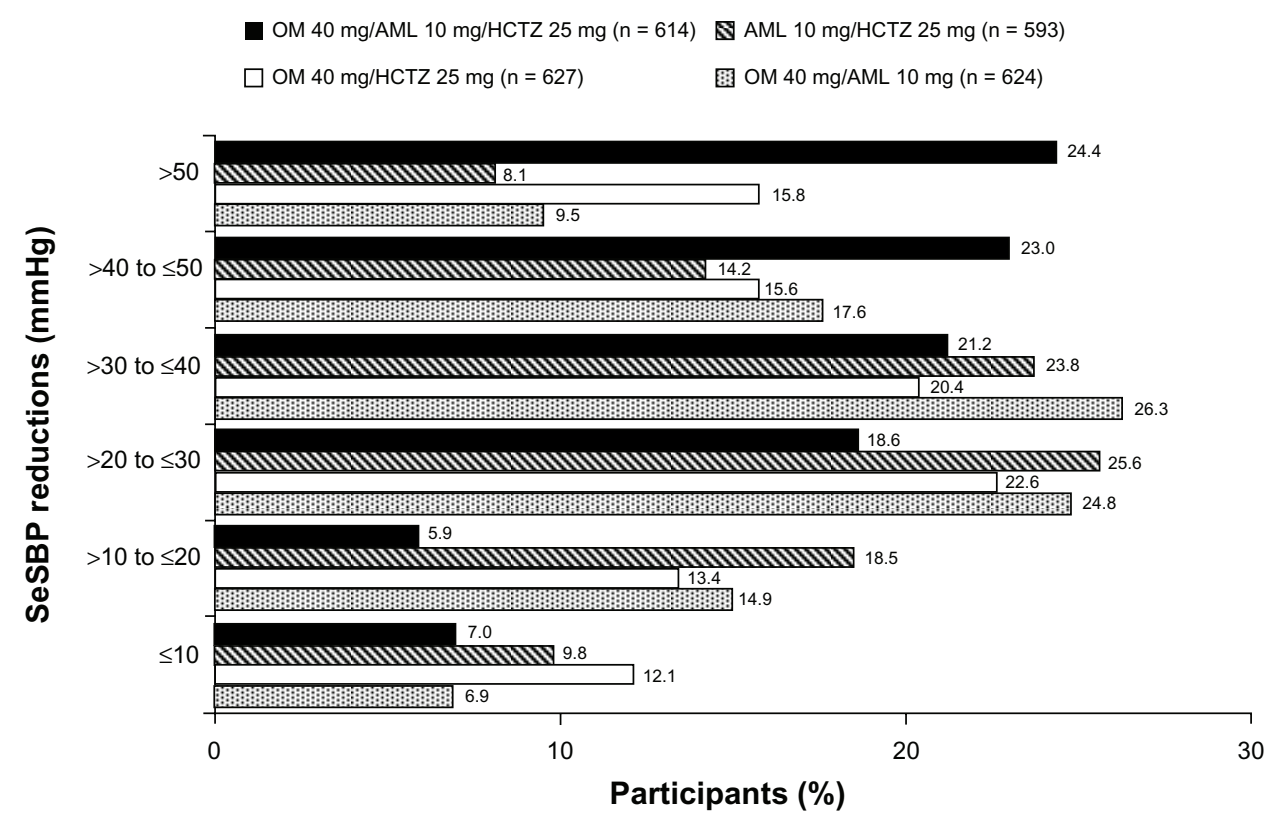

Figure 2 Frequency distribution in SeSBP at week 12 from baseline (last observation carried forward) by treatment. Abbreviations: SeSBP, seated systolic blood pressure; OM, olmesartan medoxomil; AML, amlodipine besylate; HCTZ, hydrochlorothiazide; $n$, number. 

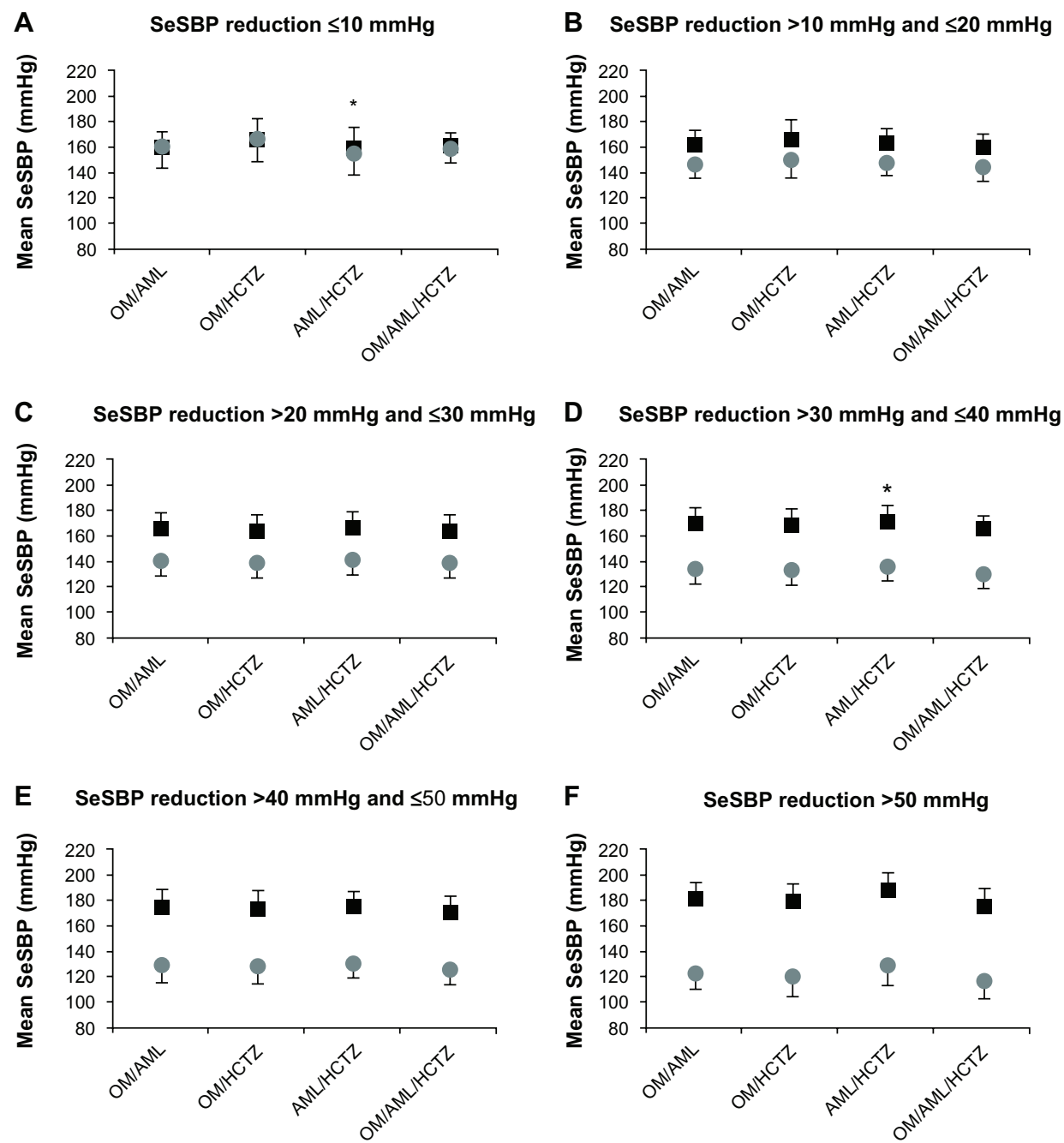

Figure 3 Mean baseline and week 12 SeSBP (last observation carried forward) by treatment.

Notes: Mean baseline and week $12 \mathrm{SeSBP}$ (last observation carried forward) by treatment among participants with a $(\mathbf{A}) \leq 10 \mathrm{mmHg}(\mathbf{B})>10 \mathrm{mmHg}$ and $\leq 20 \mathrm{mmHg}$; (C) $>20 \mathrm{mmHg}$ and $\leq 30 \mathrm{mmHg}$; (D) $>30 \mathrm{mmHg}$ and $\leq 40 \mathrm{mmHg}$; (E) $>40 \mathrm{mmHg}$ and $\leq 50 \mathrm{mmHg}$; and (F) $>50 \mathrm{mmHg}$ SeSBP reduction from baseline. Please see Figure 2 for the number of participants in each category. Error bars depict the standard deviation. ${ }^{*} P<0.05$ for the least squares mean reduction in SeSBP, OM/AML/HCTZ versus dual-combination treatment.

Abbreviations: SeSBP, seated systolic blood pressure; OM, olmesartan medoxomil (40 mg); AML, amlodipine besylate (I0 mg); HCTZ, hydrochlorothiazide (25 mg).

BP targets (Figures 4 and 5), particularly with SeSBP reductions $>30 \mathrm{mmHg}$.

\section{Safety}

No new safety concerns were identified with the tripleor dual-combination treatments that were not known to occur with the individual-component treatments. In total, $1287 / 2302$ study participants (55.9\%) had a treatment-emergent adverse event (TEAE), and 585 participants (25.4\%) had a drug-related TEAE. ${ }^{11}$ Most TEAEs were mild or moderate in severity. The prevalence and severity of adverse events did not appear to be related to either treatment or the degree of categorical SeSBP reduction (Table 1).
TEAEs with triple-combination treatment OM $40 \mathrm{mg} /$ AML $10 \mathrm{mg} / \mathrm{HCTZ} 25 \mathrm{mg}$ occurred in 56.3\% and 60.5\% of participants with SeSBP reductions of $\leq 40 \mathrm{mmHg}$ and $>40 \mathrm{mmHg}$, respectively. Drug-related TEAEs occurred in $26.4 \%$ and $30.1 \%$ of participants with SeSBP reductions of $\leq 40 \mathrm{mmHg}$ and $>40 \mathrm{mmHg}$, respectively. For the total study population, $2.3 \%$ of participants discontinued study participation because of a TEAE, and $1.4 \%$ of participants discontinued study participation because of a drug-related TEAE. ${ }^{11}$ Discontinuations related to adverse events were more prevalent in participants receiving triple-combination treatment, particularly in participants with a $\leq 40 \mathrm{mmHg}$ reduction in SeSBP across treatment groups (Table 1). 
A

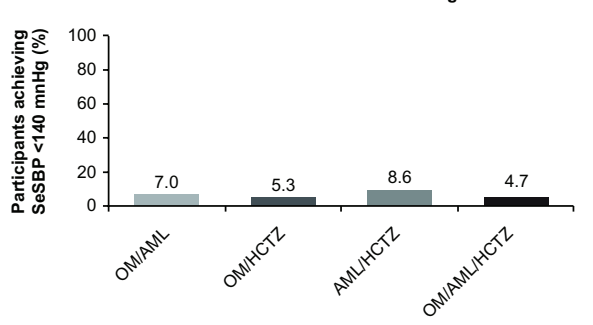

C

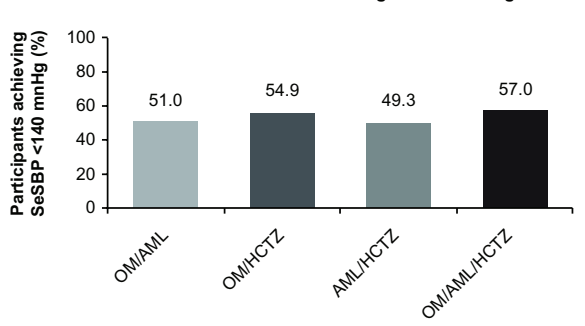

E SeSBP reduction $>40 \mathrm{mmHg}$ and $\leq 50 \mathrm{mmHg}$

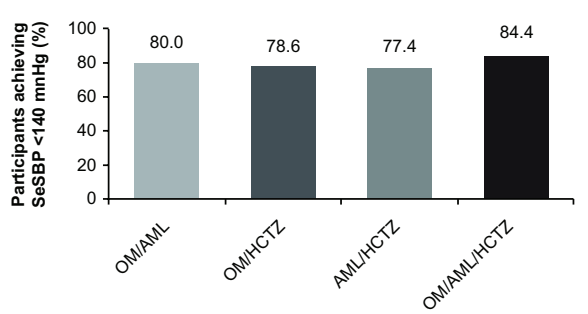

B

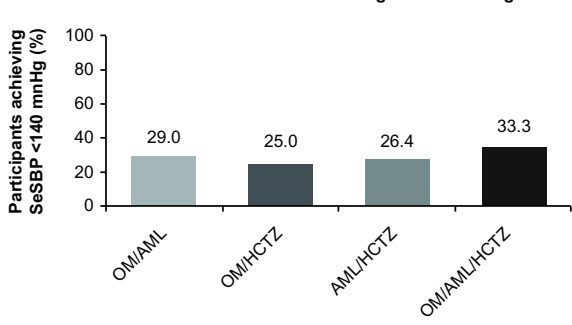

D

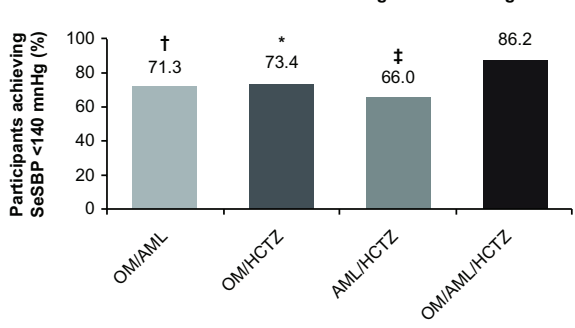

$\mathbf{F}$

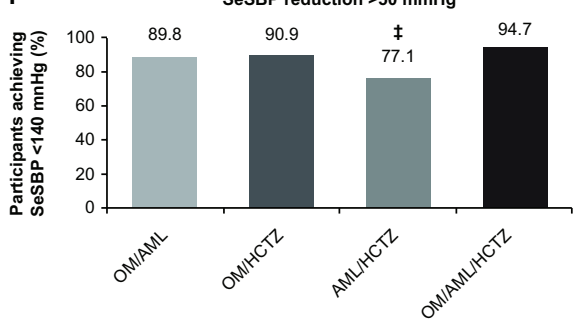

Figure 4 Proportion of participants achieving a SeSBP target of $<140 \mathrm{mmHg}$ at week 12 (last observation carried forward).

Notes: Proportion of participants achieving a SeSBP target of $<140 \mathrm{mmHg}$ at week 12 (last observation carried forward) with a $(\mathbf{A}) \leq 10 \mathrm{mmHg}$; (B) $>10 \mathrm{mmHg}$ and $\leq 20 \mathrm{mmHg}$; (C) $>20 \mathrm{mmHg}$ and $\leq 30 \mathrm{mmHg}$;(D) $>30 \mathrm{mmHg}$ and $\leq 40 \mathrm{mmHg}$; (E) $>40 \mathrm{mmHg}$ and $\leq 50 \mathrm{mmHg}$; and (F) $>50 \mathrm{mmHg}$ SeSBP reduction from baseline. Please see Figure 2 for the number of participants in each category. $* P<0.05$; ${ }^{\dagger} P \leq 0.01$; ${ }^{\ddagger} P \leq 0.00 \mathrm{I}$, OM/AML/HCTZ versus dual-combination treatment.

Abbreviations: SeSBP, seated systolic blood pressure; OM, olmesartan medoxomil (40 mg); AML, amlodipine besylate (I0 mg); HCTZ, hydrochlorothiazide (25 mg).

Across treatment groups, the most common TEAEs were dizziness $(7.0 \%)$, headache $(6.5 \%)$, peripheral edema (6.0\%), and fatigue (5.4\%). TEAEs that occurred in $\geq 5 \%$ of study participants in any treatment/SeSBP reduction category included these four events, as well as upper respiratory tract infection, nausea, and hypokalemia (low potassium) (Table 1). Peripheral edema was more prevalent in participants receiving AML $10 \mathrm{mg}$ with or without $\mathrm{OM}$ $40 \mathrm{mg}$ or HCTZ $25 \mathrm{mg}$, irrespective of SeSBP reduction; hypokalemia was more prevalent in participants receiving AML 10 mg/HCTZ 25 mg, irrespective of SeSBP reduction; and dizziness was more prevalent in participants receiving OM $40 \mathrm{mg} / \mathrm{HCTZ} 25 \mathrm{mg}$ with or without AML $10 \mathrm{mg}$ with a $>40 \mathrm{mmHg}$ reduction in SeSBP (Table 1). The prevalence of headache, upper respiratory tract infection, fatigue, and nausea did not appear to be related to treatment or degree of SeSBP reduction (Table 1). The prevalence of cough, hypotension, and orthostatic hypotension was low across treatments regardless of categorical SeSBP reduction (Table 1).
In the TRINITY study population, small changes were observed in each serum chemistry and hematologic parameter across the treatment groups (data not shown). Key chemistry parameters included alanine transaminase, aspartate transaminase, blood urea nitrogen, creatinine, sodium, potassium, and bicarbonate; key hematology parameters included hemoglobin, hematocrit, white blood cell count, and platelet count. These changes had no apparent relationship to treatment regimen and were not considered clinically significant. ${ }^{11}$

\section{Discussion}

This prespecified analysis of a large, multicenter, randomized, parallel-group trial demonstrated the efficacy of triple-combination treatment with OM $40 \mathrm{mg} / \mathrm{AML}$ $10 \mathrm{mg} / \mathrm{HCTZ} 25 \mathrm{mg}$ in lowering elevated SBP. Nearly 50\% of participants randomized to triple-combination treatment achieved $>40 \mathrm{mmHg}$ and nearly $25 \%$ achieved $>50 \mathrm{mmHg}$ reduction in SeSBP. As a result, significantly more participants receiving triple-combination treatment achieved 

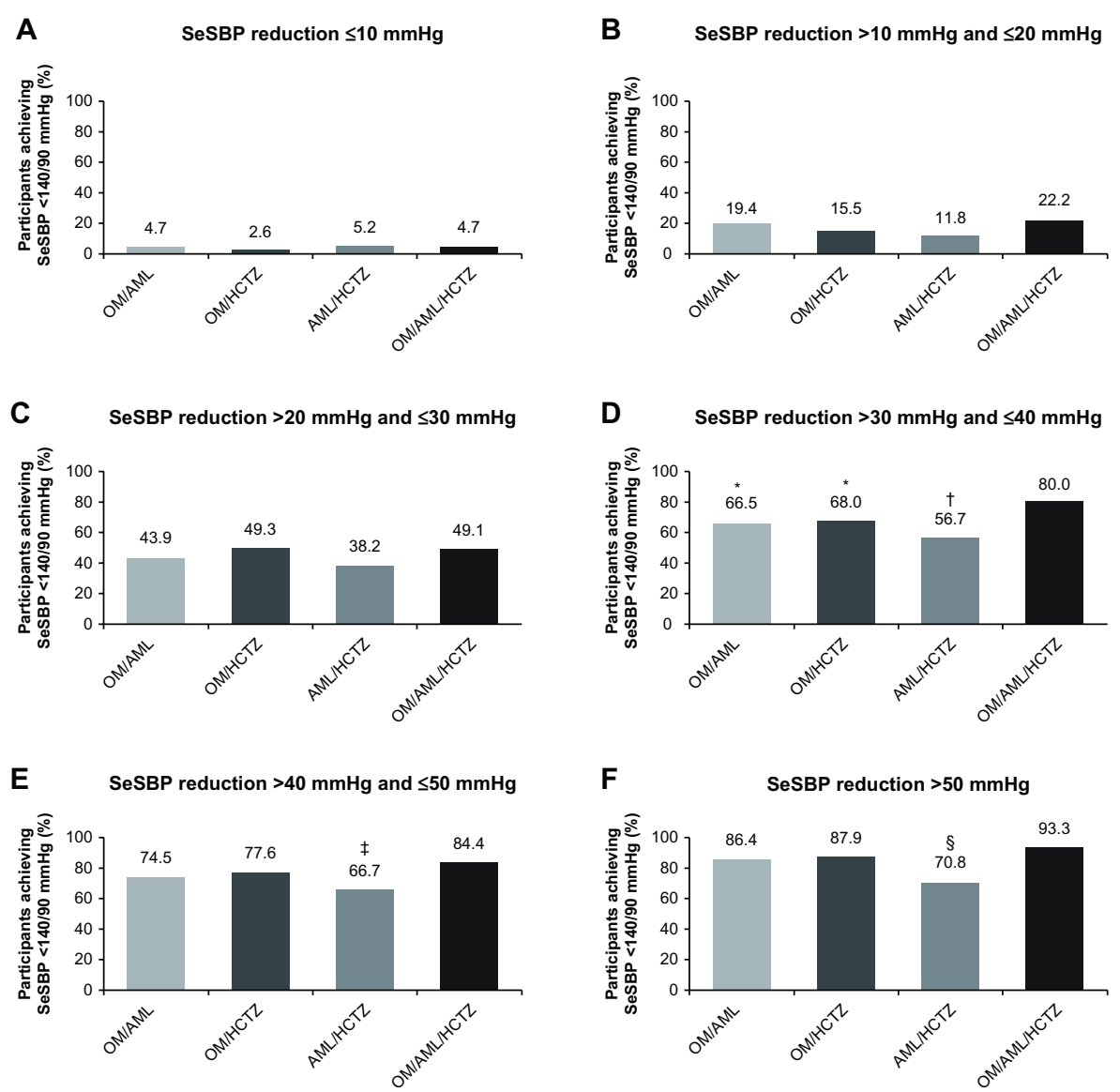

Figure 5 Proportion of participants achieving a SeBP target of $<140 / 90 \mathrm{mmHg}$ at week 12 (last observation carried forward).

Notes: Proportion of participants achieving a SeBP target of $<140 / 90 \mathrm{mmHg}$ at week 12 (last observation carried forward) among participants with a (A) $\leq 10 \mathrm{mmHg}$; (B) $>10 \mathrm{mmHg}$ and $\leq 20 \mathrm{mmHg}$; (C) $>20 \mathrm{mmHg}$ and $\leq 30 \mathrm{mmHg}$ (D) $>30 \mathrm{mmHg}$ and $\leq 40 \mathrm{mmHg}$ (E) $>40 \mathrm{mmHg}$ and $\leq 50 \mathrm{mmHg}$; and (F) $>50 \mathrm{mmHg}$ SeSBP reduction from baseline. Please see Figure 2 for the number of participants in each category. ${ }^{*} P<0.05 ;{ }^{\dagger} P<0.000$ I; ${ }^{\ddagger} P \leq 0.01$ I; $\$ P \leq 0.00 \mathrm{I}, 0 \mathrm{OM} / \mathrm{AML} / \mathrm{HCTZ}$ versus dual-combination treatment.

Abbreviations: SeBP, seated blood pressure; OM, olmesartan medoxomil (40 mg); AML, amlodipine besylate (10 mg); HCTZ, hydrochlorothiazide (25 mg).

the SeSBP target of $<140 \mathrm{mmHg}$. In addition, triplecombination treatment was well tolerated; the prevalence of TEAEs in the triple-combination treatment group was similar to that in the dual-combination treatment groups, both in participants with and without a $>40 \mathrm{mmHg}$ reduction in SeSBP.

As early as 1971, the Framingham Heart Study demonstrated that SBP more accurately reflects the risk of hypertension-associated complications than DBP; this finding has subsequently been confirmed in numerous evaluations..$^{3,6,12,13}$ A longitudinal assessment of $>18,000$ individuals found that the addition of SBP to a multivariate logistic regression model that already included DBP significantly enhanced the assessment of coronary heart disease mortality risk. However, the reverse was not true: addition of DBP to a model that already included SBP did not improve risk assessment. ${ }^{13}$ Similarly, a meta-analysis of data from eight hypertension trials found that total mortality was positively correlated with SBP but not with DBP in individuals $\geq 60$ years of age. ${ }^{3}$

Similarly, improvements in cardiovascular outcomes have been shown to be more closely related to reductions in SBP than $\mathrm{DBP}^{8}$ In a meta-analysis of data from ten hypertension trials, active treatment decreased BP (weighted mean reduction: $21.9 / 13.7 \mathrm{mmHg}$ ) and significantly reduced cardiovascular events (cardiovascular events included stroke, coronary heart disease, and other fatal and nonfatal vascular disorders as defined in each trial). ${ }^{8}$ However, this reduction in cardiovascular events was essentially identical and remained statistically significant across quartiles of DBP reduction, which indicates that the reduction in DBP had little, if any, effect on clinical outcomes independent of SBP reduction. ${ }^{8}$

Data from numerous clinical trials support the beneficial effects of reducing BP on cardiovascular and renal events, and some trials support the beneficial effects of reducing elevated SBP on cardiovascular and renal endpoints. ${ }^{14-26}$ 


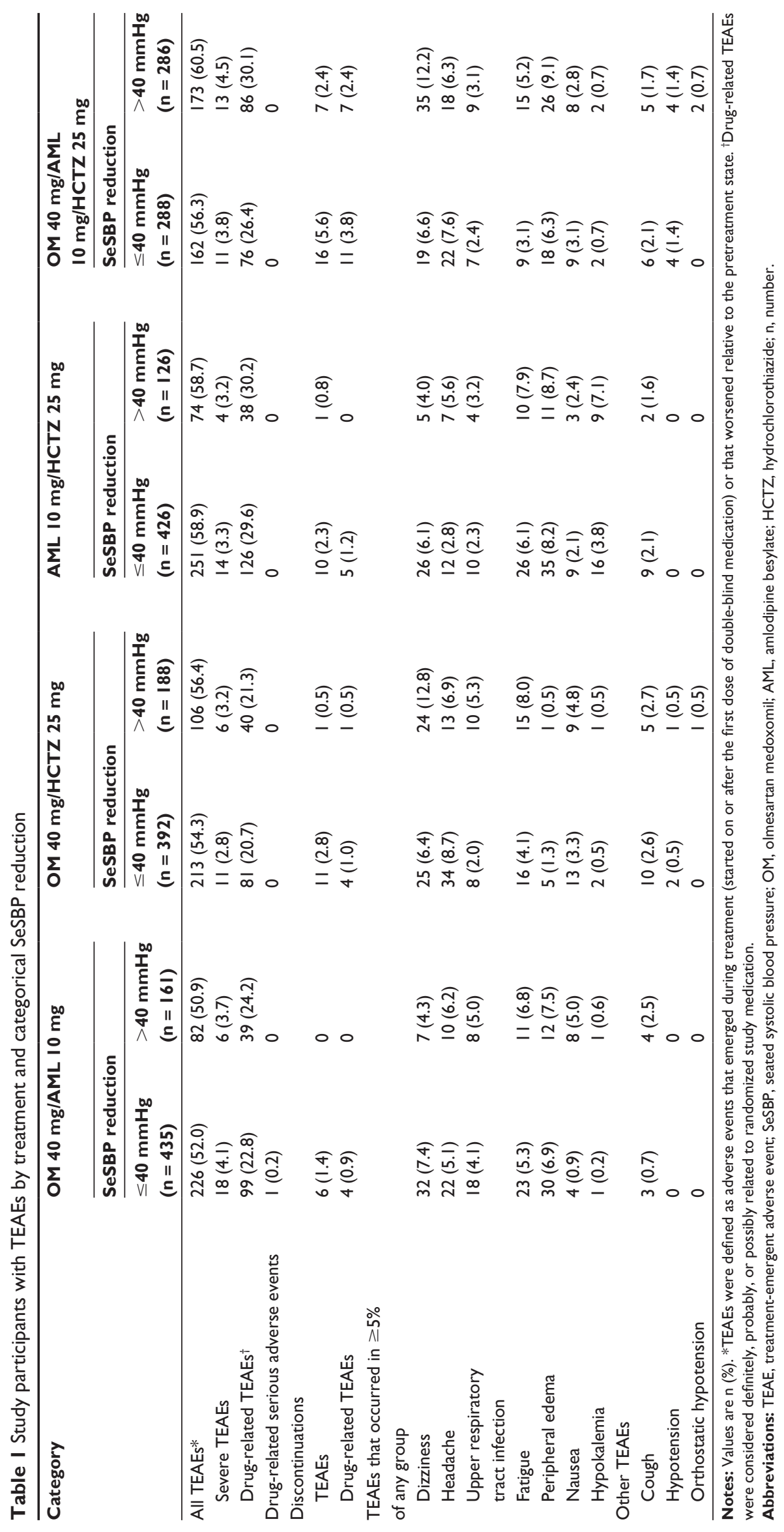


A meta-analysis of data from nearly 200,000 patients participating in 31 clinical trials found the risk of major cardiovascular events was reduced by $11.9 \%$ (95\% confidence interval [CI]: $5.3 \%-18.0 \%$ ) in individuals $<65$ years of age and $9.1 \%$ (95\% CI: $3.6 \%-14.3 \%$ ) in individuals $\geq 65$ years of age for each $5 \mathrm{mmHg}$ reduction in $\mathrm{SBP}{ }^{26} \mathrm{As}$ a result, current US guidelines recommend reducing SBP to $<140 \mathrm{mmHg}$ $(<130 \mathrm{mmHg}$ in patients with concomitant diabetes or chronic kidney disease). ${ }^{2}$

Studies have suggested that SBP may be more difficult to control than DBP. Although $90 \%$ of patients in ALLHAT and $91 \%$ of patients in the Controlled Onset Verapamil Investigation of Cardiovascular Endpoints (CONVINCE) trial achieved DBP control, only $64 \%$ and $68 \%$ of patients in these trials, respectively, achieved SBP control despite the fact that $>60 \%$ were taking $\geq 2$ and some were taking $\geq 4$ antihypertensive agents. ${ }^{9,27}$

As a result, resistant hypertension (the inability to achieve a patient's BP goal despite concurrent use of optimal doses of three antihypertensive agents of different classes, including a diuretic) is typically related to an inability to control SBP, not DBP. ${ }^{28}$ Although the exact prevalence of resistant hypertension in the US is unknown, ${ }^{28}$ it is clearly substantial. Overall, $30.1 \%$ of participants randomized to triple-combination treatment in the present trial did not achieve the SeBP target of $<140 / 90 \mathrm{mmHg}$ ( $26.4 \%$ did not achieve the SeSBP target of $<140 \mathrm{mmHg}$ ) and could be classified as having resistant hypertension.

Figure 3 shows that participants with the largest SeSBP reductions also had the highest baseline SeSBP. However, there were some participants with high baseline SeSBP who did not achieve large SeSBP reductions. These participants, in addition to having elevated SeSBP, may have had demographic and baseline characteristics that resulted in variations of physiological responsiveness to treatment, which resulted in an inability to reach BP targets and a classification of resistant hypertension.

Treatment adherence is an important component of BP control. A recent evaluation using Medication Event Monitoring System caps to assess adherence found that mean SBP and DBP, respectively, were $11.6 \mathrm{mmHg}$ and $7.7 \mathrm{mmHg}$ higher (both $P<0.001$ ) in patients after 7 days of poor $(<60 \%)$ versus excellent $(100 \%)$ adherence. ${ }^{29}$ The use of multiple antihypertensive agents to reach BP targets may adversely affect adherence, leading to poorer BP control. This is especially relevant because most patients with hypertension will require two or more agents to reach their BP target, with approximately $25 \%$ of patients requiring three or more agents. ${ }^{9,30-35}$ A retrospective evaluation of data from approximately 85,000 patients in the Kaiser Permanente system found an inverse correlation between the number of antihypertensive medications prescribed and adherence. ${ }^{36}$ Consistent with this, several evaluations have shown that the use of fixed-dose, single-pill combination therapy to simplify the therapeutic regimen and reduce pill burden significantly improves adherence relative to free-dose combination therapy. ${ }^{37-41}$

Because most patients with hypertension (especially those $>50$ years of age) will reach their DBP goal once their SBP goal is reached, the treatment of hypertension should focus primarily on controlling SBP; SBP targets are typically more difficult to achieve than DBP targets, and SBP levels are more closely correlated with cardiovascular risk than DBP levels. ${ }^{2}$ Single-pill combination therapy may increase patient adherence and enable more patients to achieve SBP targets. As shown in the present study, OM $40 \mathrm{mg} / \mathrm{AML} 10 \mathrm{mg} / \mathrm{HCTZ}$ $25 \mathrm{mg}$ may be a safe and effective option in these patients.

\section{Acknowledgments}

Research funds for this study, study medication, and preparation of the manuscript were provided by Daiichi Sankyo, Inc, Parsippany, NJ, USA. Editorial support for this article was provided by Vrinda Mahajan of Peloton Advantage, LLC, Parsippany, NJ, USA. The opinions expressed in the present article are those of the authors. The authors received no honoraria/fee for service or other form of financial support related to the development of this article.

\section{Disclosure}

Dr Sugimoto has received grant/research support from Daiichi Sankyo, Inc. Dr Chrysant has served as a consultant and speakers' bureau member for and received grant/research support and honoraria from Daiichi Sankyo, Inc. Dr Melino, Dr Lee, and Victor Fernandez are employees of Daiichi Sankyo, Inc. Dr Heyrman is a former employee of Daiichi Sankyo, Inc. The authors report no other conflicts of interest in this work.

\section{References}

1. Go AS, Mozaffarian D, Roger VL, et al; for American Heart Association Statistics Committee and Stroke Statistics Subcommittee. Executive summary: heart disease and stroke statistics - 2013 update: a report from the American Heart Association. Circulation. 2013;127(1):143-152.

2. Chobanian AV, Bakris GL, Black HR, et al; for Joint National Committee on Prevention, Detection, Evaluation, and Treatment of High Blood Pressure, National Heart, Lung, and Blood Institute; National High Blood Pressure Education Program Coordinating Committee. Seventh report of the Joint National Committee on Prevention, Detection, Evaluation, and Treatment of High Blood Pressure. Hypertension. 2003;42(6):1206-1252. 
3. Staessen JA, Gasowski J, Wang JG, et al. Risks of untreated and treated isolated systolic hypertension in the elderly: meta-analysis of outcome trials [published correction appears in Lancet. 2001;357(9257):724]. Lancet. 2000;355(9207):865-872.

4. Wright JD, Hughes JP, Ostchega Y, Yoon SS, Nwankwo T. Mean systolic and diastolic blood pressure in adults aged 18 and over in the United States, 2001-2008. Natl Health Stat Report. 2011;(35):1-22, 24.

5. Franklin SS, Jacobs MJ, Wong ND, L'Italien GJ, Lapuerta P. Predominance of isolated systolic hypertension among middle-aged and elderly US hypertensives: analysis based on National Health and Nutrition Examination Survey (NHANES) III. Hypertension. 2001; 37(3):869-874.

6. Lewington S, Clarke R, Qizilbash N, Peto R, Collins R; for Prospective Studies Collaboration. Age-specific relevance of usual blood pressure to vascular mortality: a meta-analysis of individual data for one million adults in 61 prospective studies [published correction appears in Lancet. 2003;361(9362):1060]. Lancet. 2002;360(9349): 1903-1913.

7. Aronow WS, Fleg JL, Pepine CJ, et al. ACCF/AHA 2011 expert consensus document on hypertension in the elderly: a report of the American College of Cardiology Foundation Task Force on Clinical Expert Consensus Documents developed in collaboration with the American Academy of Neurology, American Geriatrics Society, American Society for Preventive Cardiology, American Society of Hypertension, American Society of Nephrology, Association of Black Cardiologists, and European Society of Hypertension. J Am Coll Cardiol. 2011;57(20):2037-2114.

8. Wang JG, Staessen JA, Franklin SS, Fagard R, Gueyffier F. Systolic and diastolic blood pressure lowering as determinants of cardiovascular outcome. Hypertension. 2005;45(5):907-913.

9. Cushman WC, Ford CE, Cutler JA, et al; for ALLHAT Collaborative Research Group. Success and predictors of blood pressure control in diverse North American settings: the Antihypertensive and LipidLowering Treatment to Prevent Heart Attack Trial (ALLHAT). J Clin Hypertens (Greenwich). 2002;4(6):393-404.

10. Black HR. The paradigm has shifted to systolic blood pressure. J Hum Hypertens. 2004;18 Suppl 2:S3-S7.

11. Oparil S, Melino M, Lee J, Fernandez V, Heyrman R. Triple therapy with olmesartan medoxomil, amlodipine besylate, and hydrochlorothiazide in adult patients with hypertension: the TRINITY multicenter, randomized, double-blind, 12-week, parallel-group study. Clin Ther. 2010;32(7):1252-1269.

12. Kannel WB, Gordon T, Schwartz MJ. Systolic versus diastolic blood pressure and risk of coronary heart disease: the Framingham study. Am J Cardiol. 1971;27(4):335-346.

13. Lichtenstein MJ, Shipley MJ, Rose G. Systolic and diastolic blood pressures as predictors of coronary heart disease mortality in the Whitehall study. BMJ (Clin Res Ed). 1985;291(6490):243-245.

14. Prevention of stroke by antihypertensive drug treatment in older persons with isolated systolic hypertension: final results of the Systolic Hypertension in the Elderly Program (SHEP). SHEP Cooperative Research Group. JAMA. 1991;265(24):3255-3264.

15. Staessen JA, Fagard R, Thijs L, et al. Randomised double-blind comparison of placebo and active treatment for older patients with isolated systolic hypertension. The Systolic Hypertension in Europe (Syst-Eur) Trial Investigators. Lancet. 1997;350(9080):757-764.

16. Hansson L, Zanchetti A, Carruthers SG, et al. Effects of intensive blood-pressure lowering and low-dose aspirin in patients with hypertension: principal results of the Hypertension Optimal Treatment (HOT) randomised trial. HOT Study Group. Lancet. 1998; 351(9118):1755-1762.

17. Effects of ramipril on cardiovascular and microvascular outcomes in people with diabetes mellitus: results of the HOPE study and MICRO-HOPE substudy. Heart Outcomes Prevention Evaluation Study Investigators [published correction appears in Lancet. 2000;356(9232):860]. Lancet. 2000;355(9200):253-259.
18. Estacio RO, Jeffers BW, Gifford N, Schrier RW. Effect of blood pressure control on diabetic microvascular complications in patients with hypertension and type 2 diabetes. Diabetes Care. 2000;23 Suppl 2: B54-B64.

19. Lithell H, Hansson L, Skoog I, et al; for SCOPE Study Group. The Study on Cognition and Prognosis in the Elderly (SCOPE): principal results of a randomized double-blind intervention trial. $J$ Hypertens. 2003;21(5):875-886.

20. Berl T, Hunsicker LG, Lewis JB, et al; for Collaborative Study Group. Impact of achieved blood pressure on cardiovascular outcomes in the Irbesartan Diabetic Nephropathy Trial. J Am Soc Nephrol. 2005;16(7):2170-2179.

21. Liu L, Zhang Y, Liu G, Li W, Zhang X, Zanchetti A; for FEVER Study Group. The Felodipine Event Reduction (FEVER) Study: a randomized long-term placebo-controlled trial in Chinese hypertensive patients. J Hypertens. 2005;23(12):2157-2172.

22. Pohl MA, Blumenthal S, Cordonnier DJ, et al. Independent and additive impact of blood pressure control and angiotensin II receptor blockade on renal outcomes in the irbesartan diabetic nephropathy trial: clinical implications and limitations. J Am Soc Nephrol. 2005;16(10):3027-3037.

23. Arima H, Chalmers J, Woodward M, et al; for PROGRESS Collaborative Group. Lower target blood pressures are safe and effective for the prevention of recurrent stroke: the PROGRESS trial. J Hypertens. 2006;24(6):1201-1208.

24. Patel A, MacMahon S, Chalmers J, et al; for ADVANCE Collaborative Group. Effects of a fixed combination of perindopril and indapamide on macrovascular and microvascular outcomes in patients with type 2 diabetes mellitus (the ADVANCE trial): a randomised controlled trial. Lancet. 2007;370(9590):829-840.

25. Beckett NS, Peters R, Fletcher AE, et al; for HYVET Study Group. Treatment of hypertension in patients 80 years of age or older. $N E n g l$ J Med. 2008;358(18):1887-1898.

26. Turnbull F, Neal B, Ninomiya T, et al; for Blood Pressure Lowering Treatment Trialists' Collaboration. Effects of different regimens to lower blood pressure on major cardiovascular events in older and younger adults: meta-analysis of randomised trials. BMJ. 2008;336(7653): $1121-1123$.

27. Black HR, Elliott WJ, Neaton JD, et al. Baseline characteristics and early blood pressure control in the CONVINCE Trial. Hypertension. 2001;37(1):12-18.

28. Calhoun DA, Jones D, Textor S, et al. Resistant hypertension: diagnosis, evaluation, and treatment. A scientific statement from the American Heart Association Professional Education Committee of the Council for High Blood Pressure Research. Hypertension. 2008;51(6): $1403-1419$

29. Rose AJ, Glickman ME, D'Amore MM, Orner MB, Berlowitz D, Kressin NR. Effects of daily adherence to antihypertensive medication on blood pressure control. J Clin Hypertens (Greenwich). 2011;13(6): 416-421.

30. Dahlöf B, Sever PS, Poulter NR, et al; for ASCOT Investigators. Prevention of cardiovascular events with an antihypertensive regimen of amlodipine adding perindopril as required versus atenolol adding bendroflumethiazide as required, in the Anglo-Scandinavian Cardiac Outcomes Trial-Blood Pressure Lowering Arm (ASCOT-BPLA): a multicentre randomised controlled trial. Lancet. 2005;366(9489): 895-906.

31. Wright JT Jr, Dunn JK, Cutler JA, et al; for ALLHAT Collaborative Research Group. Outcomes in hypertensive black and nonblack patients treated with chlorthalidone, amlodipine, and lisinopril. JAMA. 2005; 293(13):1595-1608.

32. Chapman N, Chang CL, Dahlöf B, Sever PS, Wedel H, Poulter NR; for ASCOT Investigators. Effect of doxazosin gastrointestinal therapeutic system as third-line antihypertensive therapy on blood pressure and lipids in the Anglo-Scandinavian Cardiac Outcomes Trial. Circulation. 2008;118(1):42-48. 
33. Feldman RD, Zou GY, Vandervoort MK, Wong CJ, Nelson SA, Feagan BG. A simplified approach to the treatment of uncomplicated hypertension: a cluster randomized, controlled trial. Hypertension. 2009;53(4):646-653.

34. Jamerson K, Weber MA, Bakris GL, et al; for ACCOMPLISH Trial Investigators. Benazepril plus amlodipine or hydrochlorothiazide for hypertension in high-risk patients. $N$ Engl J Med. 2008;359(23): 2417-2428.

35. Gradman AH, Basile JN, Carter BL, Bakris GL; for American Society of Hypertension Writing Group. Combination therapy in hypertension [published correction appears in J Am Soc Hypertens. 2010;4(2):99]. J Am Soc Hypertens. 2010;4(1):42-50.

36. Fung V, Huang J, Brand R, Newhouse JP, Hsu J. Hypertension treatment in a Medicare population: adherence and systolic blood pressure control. Clin Ther. 2007;29(5):972-984.

37. Brixner DI, Jackson KC 2nd, Sheng X, Nelson RE, Keskinasian A. Assessment of adherence, persistence, and costs among valsartan and hydrochlorothiazide retrospective cohorts in free- and fixed-dose combinations. Curr Med Res Opin. 2008;24(9):2597-2607.
38. Hess G, Hill J, Lau H, Dastani H, Chaudhari P. Medication utilization patterns and hypertension-related expenditures among patients who were switched from fixed-dose to free-combination antihypertensive therapy. P T. 2008;33(11):652-666.

39. Malesker MA, Hilleman DE. Comparison of amlodipine/valsartan fixed-dose combination therapy and conventional therapy. Manag Care. 2010;19(7):36-42.

40. Yang W, Chang J, Kahler KH, et al. Evaluation of compliance and health care utilization in patients treated with single pill vs free combination antihypertensives. Curr Med Res Opin. 2010;26(9):2065-2076.

41. Zeng F, Patel BV, Andrews L, Frech-Tamas F, Rudolph AE. Adherence and persistence of single-pill ARB/CCB combination therapy compared to multiple-pill ARB/CCB regimens. Curr Med Res Opin. 2010;26(12):2877-2887.

\section{Publish your work in this journal}

Integrated Blood Pressure Control is an international, peer-reviewed open-access journal focusing on the integrated approach to managing hypertension and risk reduction. Treating the patient and comorbidities together with diet and lifestyle modification and optimizing healthcare resources through a multidisciplinary team approach constitute key

\section{Dovepress}

features of the journal. This journal is indexed on American Chemical Society's Chemical Abstracts Service (CAS). The manuscript management system is completely online and includes a very quick and fair peerreview system, which is all easy to use. Visit http://www.dovepress.com/ testimonials.php to read real quotes from published authors.

Submit your manuscript here: http://www.dovepress.com/integrated-blood-pressure-control-journal 